Article

\title{
Freedom of Expression and Alternatives for Internet Governance: Prospects and Pitfalls
}

\author{
Emma Ricknell \\ Department of Political Science, Linnaeus University, 35195 Växjö, Sweden; E-Mail: emma.ricknell@Inu.se
}

Submitted: 28 May 2020 | Accepted: 7 July 2020 | Published: 15 October 2020

\begin{abstract}
This article dives into the ongoing debate on how to address concerns of personal safety and respect online, as well as consequences for exposure to polarizing and in various ways harmful information, while at the same time safeguarding the democratic essentials of freedom of expression and participation. It does so by examining the issue from a less common angle, namely who governs the Internet and the platforms where much of the toxic material appears. By applying a model of free speech regulation conceptualized by legal scholar Jack Balkin (2018a, 2018b), the article explores different theoretical future scenarios of Internet governance involving three main players, namely governments, private companies, and speakers. The analysis finds that depending on which player is at the forefront, the outcomes from the standpoint of participation and freedom of speech may be drastically different. While there is potential for transformation that can enable more ownership, transparency, and agency for citizens and news media, some potential paths will place ever-increasing control over the interests of users.
\end{abstract}

\section{Keywords}

decentralization; freedom of expression; Internet governance; social media platforms; walled garden

\section{Issue}

This article is part of the issue "Freedom of Expression, Democratic Discourse and the Social Media" edited by Maria Elliot (Linnaeus University, Sweden) and Kristoffer Holt (Linnaeus University, Sweden).

(C) 2020 by the author; licensee Cogitatio (Lisbon, Portugal). This article is licensed under a Creative Commons Attribution 4.0 International License (CC BY).

\section{Introduction}

For those who remember the dawn of the modern Internet, the sense of unlimited possibilities may be reminiscent. Not only did we gain access to information in a completely different way at the touch of a mouse button, but could connect with people in previously unthinkable ways. With the Internet decentralizing communication, putting new forms of speech and cultural expressions into the hands of participants, a radical enhancement of democracy was seen as a possibility (Poster, 1997). Over time, the Internet via social media platforms indeed grew into an important new tool in citizen struggles for freedom and democracy (Chadwick \& Howard, 2009), such as during the Arab Spring in 2011 (Allagui, 2014).

Our modern Internet however also features aspects that fit poorly with the idea of participation in a furtherance of democracy on equal grounds. There is considerable research on the prevalence of harmful, polarizing content online (e.g., Assimakopoulos, Baider, \& Millar, 2017; Harmer \& Lumdsen, 2019; Keipi, Näsi, Oksanen, \& Räsänen, 2017), content which may have an effect on how targeted groups participate online, potentially silencing them altogether (van der Wilk, 2018). Online arenas where users can remain anonymous have been particularly highlighted, as they can provide breeding ground for extreme forms of online communication and sharing of very offensive information (Blumler, 2015).

Calls for regulation or even removal of such content online are frequent. The question is, how? Governments are not able to surveil all online communication and instantly block or remove harmful content (DeNardis, 2020). Moderation of content is not an easy task, involving a number of complex decisions and interpretations regarding, for example, original intent of the content, how it fits within the boundaries of current cultural taste, and public discourse in a situation where multiple competing value systems exist at the same time 
(Gillespie, 2018). In other words, rules for what is acceptable speech and how to establish rules that can meet the needs of very large and diverse groups of users is not only difficult, but inevitably political (Suzor, 2020). However, the platforms are not democratically elected public entities. Nevertheless, governments can delegate the task of regulation to such private entities (Arpagian, 2016; Coche, 2018; DeNardis, 2020). There may be multiple reasons for such public-private collaborations, including aspects of national security, where actions taken after the $9 / 11$ terror attacks in the U.S. constitute an early example (Birnhack \& Elkin-Koren, 2003). This development arguably reached new heights in connection with the Covid-19 pandemic and the World Health Organization's declaration of an on-going "infodemic" (World Health Organization, 2020). Multiple platforms, following the wishes of governments, during this time began to actively censor harmful information relating to the virus (Goldsmith \& Woods, 2020). The most dominating method is however a form of 'self-regulation,' whereby social platforms by virtue of not being liable for its content exist in a fairly laissez-faire relationship with governments (Gorwa, 2019b; Klonick, 2018). Still, platforms like Facebook, Twitter, and YouTube in various ways regulate content today (Gorwa, 2019b; Kaye, 2019; Ullman \& Tomalin, 2019), and this type of intervention of selection and deletion of content occurs constantly, even though most users never come in direct contact with it (Gillespie, 2015).

This expanding aspect of control over content however actualizes the idea of unintended consequences. In the worst-case scenario, the incredibly powerful technologies that have enabled us freedom are the very same that authoritarian regimes can obtain control over and use for repression (DeNardis, 2014, 2020; York \& Zuckerman, 2019). Alternatively, if the private companies that already function as gatekeepers for online content as exemplified above increasingly take ownership of fundamental aspects of the Internet's infrastructures, it in turn raises questions regarding transparency and concentration of power by entities not elected by democratic means (Nothias, 2020). Control of the underlying infrastructure that enables online content, generated by everyone from individual users to journalists to public agencies as part of democratic discourse, can thus have farreaching effects on the ability to speak freely.

This article departs from a perspective that once focus expands from content to who has the power to regulate it, a defining feature of the digital age appears: the friction present between freedom of speech and infrastructure (Balkin, 2014). It also applies an understanding that significant technological advancements in the near future can tip the current development towards a version involving private enterprise domination in cooperation with governments, or one where information is seen as an essential service and is governed by representative institutions, or possibly directly by citizens (Mosco, 2016). Considering how it remains very unclear as to what the preferable balance in terms of responsibility should be between tech companies, governments, and users in a policy arena that has aptly been labelled as "fragmented" (Gorwa, 2019b, p. 855), emphasis is here on possibilities, not making determinations. This article thus aims to explore these trajectories, with focus upon consequences for accessibility and freedom of expression. It does so by discussing contemporary developments specific to each of the three main players involved, meaning governments, private companies, and users, seen through the lens of legal scholar Jack Balkin's model of free speech as a triangle (Balkin, 2018a, 2018b). Depending on which player takes the lead in governing the Internet, I argue that outcomes for a free and fair Internet may diverge drastically.

\section{Internet Governance and Freedom of Speech}

A perspective based on who governs the Internet falls under the broad concept of 'Internet governance,' an understudied area of research (DeNardis, 2020) that involves the "design and administration of the technical infrastructure necessary to keep the Internet operational and the enactment of substantive policies around these technologies" (DeNardis, 2014, p. 6). The technical architecture involves a number of protocols, standards, and systems, vital yet hardly discernable to the average Internet user, reflective of a number of not only scientific advancements but "social considerations of power and authority" (DeNardis, 2014, p. 8). This article focuses less on the technical aspects but instead on one specific theme within the area of Internet governance, namely how it functions as a proxy for content control (DeNardis, 2014). Importantly, the concept of 'governance' comprises both that of governments and private intermediaries.

Scholarly discussions regarding aspects of Internet infrastructure, privacy, and speech regulation appeared among legal scholars during the dramatic growth of the public Internet in the 1990s. Among those raising warning flags were Lawrence Lessig $(1998$, p. 3), who claimed that cyberspace "has the potential to be the antithesis of a space of freedom." While not everyone agreed (Sunstein, 1995), Lessig (2000) introduced the concept of 'code is law,' which not only highlighted the underlying politics of the decisions made regarding infrastructure of the Internet and the potential for governmental restrictions on free speech via new technology, but also that there were other interests involved, namely private.

Jack Balkin similarly at an early stage identified potential issues regarding freedom of expression and the infrastructure of the Internet. In 2004, he argued that the preservation of freedom of speech would be dependent on the design of the technological infrastructure, and that in fact, the digital age would alter the entire meaning of freedom of expression (Balkin, 2004). A decade later, Balkin (2014) claimed that the infrastructure of the online platforms had over time begun to merge with the 
infrastructure of speech regulation as well as with that of public and private surveillance, altering participation in the new public sphere altogether.

\section{Free Speech in the Digital World}

The analytical framework used in this article relies on Balkin's above notion on participation in the contemporary digital world, and applies his model of free speech as a triangle per Figure 1 below (Balkin, 2018a, 2018b). In essence, the model builds upon an idea of a previous dualist model of free speech having developed into a pluralist. Dualist in the sense that before the advent of the Internet, there were two main players, namely governments, or nation-states, and speakers. The former regulated all types of speakers, which included everything from citizens to mass media. Discussions on the concept of free expression, as well as possible dangers to free expression, that were held during the 1800 s and 1900s, typically centered upon if nation-states would censor its citizens (Balkin, 2018b). The pluralist model in contrast involves multiple players, but at least three primary ones: nation-states and supra-national entities such as the European Union, private enterprises that maintain the digital infrastructure, particularly search engines and social media platforms, and finally speakers who in different ways use digital infrastructure in order to communicate. The addition of the third player, private enterprises, has over time made the dualist model less applicable, meaning that the ability for free expression in the current time period is affected by power struggles between these three main players (Balkin, 2018b).

Fundamentally, Balkin (2018a, 2018b) sees three main problems with the formation of the triangle: the risk of censorship, lack of due process and transparency, and digital surveillance. The development of these problems can be illustrated by using one type of potentially harmful online content, namely false stories portrayed as news circulating online, commonly known as 'fake news,' a term actualized particularly after the 2016 U.S. election (Allcott \& Gentzkow, 2017).

Concerns over fake content can be raised from all three corners of the triangle, yet when it comes to tackling it, the range of agency varies greatly. If the content does not explicitly violate the law, government actors in democratic nations do not typically seek out and reprimand or restrict individuals who are either producing and/or sharing it at a systematic level. Anonymity also complicates efforts. Neither do private citizens directly block the ability of others to partake in such behavior on social media platforms; complaints and reporting disturbing content are the primary measures. Instead, agency lies with the owners of the digital infrastructure, meaning the tech companies. In the case of a social media platform, violations against community standards can be cause for content being removed, or users being restricted. There are many reasons why a platform would make such a decisions, including generally wanting users to feel happy and safe, and remain on the platform. Motivated by profit, private companies will indeed inevitably delimit and restrain participation in some way (Andersson Schwarz, 2017). Another reason is to appease one of the other players, namely governments (Balkin, 2018a).

While governments may not immediately threaten a social media platform for allowing fake news, governments can persuade and in other ways cajole a company into regulating speech. Even in a situation where the tech company applies a very high bar for regulating content, if profit is more stable by cooperating with gov-

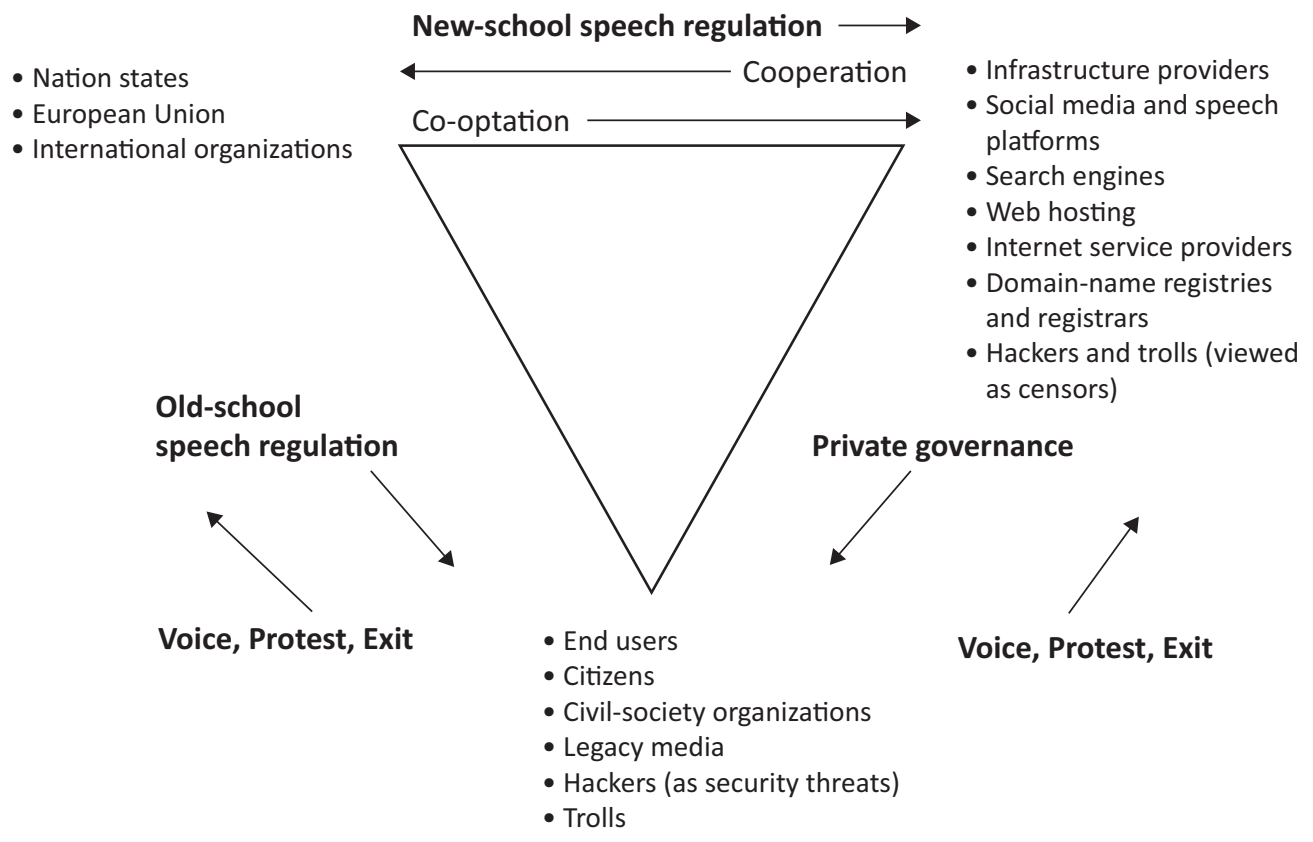

Figure 1. Balkin's (2018b) pluralist model of speech regulation. 
ernments, measures might be taken to block users or remove content (Balkin, 2018b). The bigger the company, the more capabilities it may have to regulate speech, and thus a back-and-forth cooperation/co-optation between the two players develops which Balkin (2018a, p. 1153) calls "new-school speech regulation." It can be contrasted with its "old-school" version, meaning regulation that is primarily directed toward speakers by governments, still an active feature today (Balkin, 2018b).

New-school speech regulation under the above circumstances leads to the three main issues identified by Balkin (2018a, 2018b). First of all, if told to censor or block by government, companies will tend to err on the side of caution. This can lead to overblocking or overfiltering of content, or even censorship, with tech companies incentivized more by avoiding discussions with government regarding liability concerns for content on their platform than restricting a very limited number of users (Balkin, 2018a, 2018b). The use of algorithms to moderate content has also been found to result in unfair censorship, when far too much content is removed (Kaye, 2019).

Secondly, the process of blocking or removal, whether done before or after content such as fake news materializes online, is not the result of trying the matter in a judicial process, during which for example, a determination is made regarding whether the expressed speech was protected or unprotected by law. This particular aspect is instead one where the private company has tremendous power, governing in what can be described as a "lawless" way (Suzor, 2020, p. 6). Thus, while the platforms might act upon pressure from democratically elected governments, they have in this system developed a form of privatized government, void of accountability towards users. In essence, platforms can be dubbed our 'New Governors' (Klonick, 2018).

Finally, in order to locate and track users who for example produce and/or share fake news, tech companies benefit from knowing as much as possible about them. Such capability has since long been expanding, based upon the need to be able to convince advertisers of maximum exposure to possible customers. The more an operators' infrastructure expands, the greater the capability to collect user data will be, and in turn, the greater role such companies can play in new-school speech regulation. However, on the other side of this development is increased user vulnerability to digital surveillance, the third main issue raised by Balkin (2018a, 2018b). Considering how monetization of consumer data has become the primary source of revenue for tech giants such as Google and Facebook (DeNardis, 2020), as part of a business model Zuboff (2019) calls 'surveillance capitalism,' this is arguably an ongoing process of increasing magnitude.

While there are multiple ways of conceptualizing the central aspect of free expression, the argument from a democratic standpoint in its most basic form stems from the idea that freedom of political debate and thus the flow of information and ideas must be protected in order for voters to reach a high level of knowledge (Oster, 2017). At face value, the three interlinked problems above seem like ingredients for the antithesis of a transparent, democratic system with equal access and freedom of speech. Nevertheless, as mentioned in the introduction, the current infrastructural set-up seems to be in motion (Mosco, 2016). In order to explore what such a future development may look like, in the next section the triangular model above is applied from the perspective of letting one player in the triangle each take the lead with basis in current developments. Three possible scenarios appear, labelled by their primary characteristic: government regulation, privatized 'walled gardens,' and decentralization. Each scenario is discussed below, with emphasis on consequences for the issues of the risk of censorship, lack of due process and transparency, and digital surveillance.

\section{Three Scenarios}

\subsection{Scenario 1: Government Regulation}

A situation where government takes the lead in the context of speech regulation may seem superfluous, as governments and other public entities already form a natural and essential player in our current system. However, when it comes to new-school speech regulation, actions by government can be pushed very far. In the contemporary situation, China serves as the clearest example (Romano, 2010), with grave consequences for censorship, transparency, and surveillance.

According to Moore (2018, p. 237), about a decade ago, the Chinese government saw the opportunity to, with the aid of tech companies, 'tame' the Internet and thereby establish more centralized control over society than ever before seen, resulting in "an arsenal that would make any twentieth century totalitarian state extremely jealous." This 'taming' has multiple features. Most notably there is the Chinese government's Golden Shield Project put into operation already in 2003 , a very comprehensive domestic surveillance system often referred to as 'the Great Firewall,' which enables comprehensive censoring of unwanted Internet content (Merrill, 2016, p. 90; Moore, 2018). The Chinese government has since expanded its ability to control information by establishing the country's national social credit score system, in which speech is one of the factors that determines a citizen's "trustworthiness" (DeNardis, 2020). Importantly, the Chinese government is able to accomplish this unprecedented level of centralization thanks to co-operation by tech companies, both Chinese and foreign (Moore, 2018; Romano, 2010).

Yet China is not the only empirical indicator of the possible scenario for how far a development toward increased government control and regulation can proceed. The most extreme method of controlling the Internet is to simply shut it down, colloquially known as having ac- 
cess to an "Internet kill switch" (Vargas-Leon, 2016). The shut-downs in a number of countries during the Arab Spring illustrate the reality of this development, yet is applicable not only by distinctly authoritarian governments. For example, in 2019, Russia adopted a law that allows the government to cut off the Internet entirely (Kennedy, 2019). Furthermore, among the ten governments that attempted to flip the switch between 2009 and 2014, the well-consolidated democracy Australia was among them. The idea of providing government the power to shut down the Internet legally has also been discussed in both the U.K. and the U.S. (Vargas-Leon, 2016). In other words, the norm of censoring the Internet extends globally (Deibert, Palfrey, Rohozinski, \& Zittrain, 2010).

While there may be multiple reasons as to why democratic governments establish tools to, if not shut down the Internet, at least have the ability to regulate, surveil, and censor it, the balancing act of still maintaining a free Internet might prove difficult. Independent watchdog organization Freedom House concluded in their latest report that Internet freedom declined for the ninth consecutive year globally (Shahbaz \& Funk, 2019). The organization particularly highlighted social media, pointing to platforms being surveilled by repressive governments. Yet also in democracies, mass monitoring is becoming more common across government agencies. For example, the U.K. is noted for its government's increasing interest in regulating platforms and content online, monitoring of activists from various political groups using data obtained from platforms as well as a novel form of Internet access restriction employed when Wi-Fi connections in some of London's Underground train stations were suspended by the police during protests (Shahbaz \& Funk, 2019). Such findings seem to follow the logic of research found almost a decade prior regarding the U.K.'s vast surveillance measures and, at that point, limited yet burgeoning filtering of online content (Deibert et al., 2010). In Germany, a uniquely strict and heavily criticized law that required social media platforms to swiftly remove hate speech or face hefty fines has since adoption in 2017 been found to lead to excessive blocking of content (Thomasson, 2018). The law was enacted due to an apparent frustration with some of the major U.S. social media platforms when it came to removing content considered to be unlawful (Gorwa, 2019b). Thus, even at relatively milder forms, with democratic governments at the helm of actively intervening and trying to remove deeply disturbing or unwanted content under what can be labelled as "external governance" (Gorwa, 2019b, p. 863), there is a risk of censorship, lack of due process through public-private cooperation, and surveillance.

\subsection{Scenario 2: Privatized 'Walled Gardens'}

Tech companies already play an essential role in newschool speech regulation in tandem with public entities, yet in a scenario where they are empowered, such ties could alter. Instead of moderating speech in various forms based upon governmental regulations, expanding the scope of the control that can be exercised over access in the first place constitutes another path.

One model for such expansion is a zero-rating service, providing Internet access for free but under certain conditions, such as limits on which sites can be visited. The concept has been around since the early 2010s, with a number of projects having been launched such as Google FreeZone, Wikipedia Zero, and perhaps most famously, Facebook's Free Basics initiative (Bates, Bavitz, \& Hessekiel, 2017). Proponents argue that zero rating may be the first step toward expanding access in underserved markets. Critics point to how much control over content the model enables, as well as violations of net neutrality principles by not treating all Internet traffic equally (Bates et al., 2017), in essence providing a 'walled garden' version of the Internet (DeNardis, 2020). For instance, Free Basics in India did not allow users to make voice calls and reserved Facebook the right to limit access to other services (Culpepper \& Thelen, 2020). After much public debate, the Telecom Regulatory Authority of India also ruled that Free Basics violated the country's net neutrality and thereby effectively banned all zero-ratings plans (Prasad, 2018). Facebook has nevertheless pursued the project elsewhere and it is currently available in 65 countries of which about half are in Africa (Nothias, 2020).

The idea of a walled garden service in a tech-oriented future scenario can however take on other more comprehensive infrastructural forms. In 2019, Amazon filed for U.S. Federal Communications Commission (FCC) permission to launch Project Kuiper, which if successful enables the company to become an Internet Service Provider by providing satellite broadband. Other competing companies such as SpaceX, WebOne, and Facebook have also joined in the quest to establish space-based Internet services. Arguments by proponents resemble those of zero rating-services, i.e., Internet access being provided to the worlds' many underserved consumers (Kuiper Systems LLC, 2019; Pressman, 2019).

Providing low-cost Internet service to potentially billions of users worldwide arguably constitutes an example of how private enterprise can open up the field, increasing accessibility and encouraging competition. While companies such as Amazon and Facebook did express criticism over the FCC's decision in 2017 to roll back net neutrality rules (Wattles, 2017), it is nevertheless a possibility that either one of the competing companies end up offering a very affordable service, yet with various types of restrictions. In fact, a walled garden approach could be a logical development of a continuous extension of the scope of privatized governance already established, with fuel being provided by a constant flow of highly valuable social data.

Finally, developments in institutionalization of content control among platforms provide an additional illustration of where an empowered private triangle corner could be heading. Claiming the company should 
not "make so many important decisions about free expression and safety on our own" (Zuckerberg, 2018), Facebook in May 2020 announced an independent Oversight Board to perform this task (Clegg, 2020), a move argued to represent nothing short of a "pivotal moment in the history of online speech governance" (Douek, 2019, p. 4). In the same month, Amazon's livestreaming platform Twitch announced its Safety Advisory Council, whose purpose is to shape the platform's policies on bans, for example, after accusations of unfounded bans of streamers (Greenspan, 2020). No platform board or council will however be able to provide due process in the handling of all content violation reports filed on a daily basis, nor appease all critics of censorship. Instead, and especially in combination with a walled garden Internet service, the level of control over allowed speech at a global scale can potentially increase multifold if tech companies take the lead.

\subsection{Scenario 3: Decentralization}

The third scenario involves the corner of the triangle subject to speech regulation from both other corners, namely actual speakers using digital infrastructure to communicate or access information. While speakers have the ability to exit platforms or services, or in various other ways protest or put pressure on tech companies to modify their policies (Balkin, 2018a), in the pluralist model of speech regulation, speakers take on the role of underdog. Indeed, the three main issues of censorship, lack of due process, and digital surveillance all have a direct effect on them.

A theoretical scenario where speakers are put at the helm of the development of the digital world would mean a renegotiation of the drastically unequal power relationship with the two other corners of the triangle. In the mid-1990s, cyber activist John Perry Barlow (1996, para. 8) argued for a radically free Internet existing beyond the grip of traditional governing institutions "where anyone, anywhere may express his or her beliefs, no matter how singular, without fear of being coerced into silence or conformity." Such ideas have since been dismissed as absurd and utopian (Morrison, 2009). Yet aspects of pre-commercial Internet, when individual computers connected with each other in a network without a centralized transit point (Musiani, 2015), are still highly relevant under the concept of the 'Decentralized Web' (DW).

In its very simplest form, a decentralized network removes the need for a central server and allows for multiple servers (or 'nodes') to cooperate, in essence all supplying capacity in terms of storage and computing power (Kremenova \& Gajdos, 2019). Multiple examples of DW platforms, applications, and services using peer-to-peer decentralized protocols have so far been established; current examples include the open source microblogging service Mastodon, the social network Diaspora, and the video-sharing platform PeerTube. At the core of this new technology is that communicating via a DW platform means social data is no longer centralized and owned by a tech company, meaning that mining data on users becomes more difficult (Raman, Joglekar, De Cristofaro, Sastry, \& Tyson, 2019). As the fundamentals of newschool speech regulation transform when users can be in charge of their own data, issues of digital surveillance and ultimately blocking of users in a process void of due process are no longer the same.

However, peer-to-peer digital tools such as blockchain technology may also alter another aspect of the speaker in Balkin's triangle beyond the individual user, namely news media and journalists. While still very much under development, the technology can allow journalism to be less dependent on an intermediary, meaning actors with direct or indirect interests on the information and news being produced, such as large media corporations, private enterprises, and even politicians. Reducing the distance between journalist and reader by removing centralized control mechanism in both the creation and management of news content can potentially enhance news credibility and transparency, and even limit the spread of unwanted content such as fake news (Al-Saqaf \& Edwardsson, 2019).

Finally, relating to the theme of speakers gaining more control is the idea of transforming the entire concept of what the Internet is and who should govern it. As technology advances and human dependence on the Internet increases, the argument is that the Internet should be treated not as a commercial product but as a public utility, controlled by citizens (Mosco, 2016). The concept was, for example, echoed in the 2016 U.K. Labour Party's campaign for free broadband through a new public company (Corbyn, 2016), but various more local versions of publicly owned Internet providers have been in place for years. Most notably, there is the U.S. city of Chattanooga, Tennessee, where affordable highspeed broadband has been offered by a city-owned utility since 2010 (Flessner, 2020). Additionally, local initiatives can help underserved non-metropolitan areas, such as in the U.S., where cooperatives provide almost a third of all Internet fiber service in rural areas, resembling how cooperatives in the country have historically been able to provide both electric-and telephone services rurally (Trostle, Kienbaum, Andrews, \& Mitchell, 2019). The potential for enhancing democracy via decentralized models and a different type of ownership model of the Internet itself is thus apparent, while currently existing only in minor scale.

\subsection{Discussion}

While Balkin's model of free speech as a triangle allows for an examination of the relationships between the main players involved, highlighting that we have moved far from a predominantly dualist system, the gains made from simplifying a highly complex situation create a deficit when it comes to nuance. To begin with, it means 
that relationships within the corners themselves are not fully illuminated. An example is the placing of 'legacy media' in the same corner as everyday users, an issue which can be illustrated using an on-going development. Amazon contracts with the U.S. government, particularly when it comes to web storage; the U.S. government has been projected to become Amazon's biggest customer (DePillis, 2018). In 2013, Amazon's founder Jeff Bezos purchased legacy newspaper The Washington Post, quickly raising concerns regarding potential conflicts of interest and the ability for the newspaper to maintain unbiased news reporting, especially when it came to the U.S. government (Hart, 2013). In short, the effect of new school speech regulation on citizens is thus difficult to conceptualize as being equal to that of legacy media.

Secondly, the sharp corners of the triangle obscure potential merging points. By merging points, I mean an altering of the relationship primarily speakers have to either one of the two other corners. For instance, and as alluded to in the third scenario, the relationship between governments and its citizens can feature a wholly different level of transparency and accessibility, as proposed by Mosco (2016). It is for example possible for government to, via a decentralized system, provide extensive access to personal data, such in the case of Estonia, a pioneer in terms of e-government and in the very top in terms of Internet freedom (Shahbaz \& Funk, 2019). The approach of a highly advanced e-government, where the citizen is more of an active partner than a passive consumer of services (Linders, 2012; Linders, Liao, \& Wang, 2018), can also enable new forms of cooperation and participation affecting actual policies not only between government and citizens, but also incorporating tech companies. Taiwan's participatory digital democracy and the ideas of its Digital Minister Audrey Tang (see, e.g., Tang, 2019a, 2019b, 2020) serve as an example here and apply not only to how public services are conceived, constructed, and delivered by involving multiple stakeholders, but to how the issue of harmful content online can be approached. For example, during the Covid-19 pandemic, Taiwan's strategy to counter disinformation online was called "humor over rumor," a strategy which involved government swiftly communicating factuallybased humorous 'packages' that in essence disrobed the false information instead of removing it, which was not seen as an option (Tang, 2020). In order to combat information with intent to cause harm, the strategy again did not involve takedowns of posts on social media. Instead, the government collaborated with both journalists and social media companies to ensure that a small reminder text was added to for example an image being used to promote a false narrative, enabling users to quickly identify actual versus false news material (Tang, 2020).

The second theoretically possible merging point in the triangle is between speakers and private enterprises. Considering the problematization of Internet governance and regulation being in private hands in the second scenario above, this may seem far-fetched.
Nevertheless, by conceptualizing privately owned online platforms as operating civic functions, a meeting point at least arguably appears between the two corners. As Are (2020) argues, privately owned online platforms today function as public spaces, integrated in our everyday lives and as sites for public discourse, and therefore the norms, rules, and laws, including international human rights law, which apply to off-line businesses, should apply also to them. Are (2020) defines social media platforms as "corpo-civic" to capture the hybridity of the space, where users can be seen as quasi-citizens and, following such a status, be empowered to partake in more fair, transparent, and diverse moderation of online content than current methods headed by the tech companies (Kaye, 2019). The model also involves the third corner of the triangle, government, seeing its function to among other things uphold the rights of users and maintain oversight of the platforms (Are, 2020; Kaye, 2019), thereby offering further possible meeting points between the three corners. In an alternate version, a form of 'co-governance' of the online space could also develop if civil rights organizations, part of the same corner as users, could be involved in setting up ethical frameworks and oversight for privately owned online platforms (Gorwa, 2019a, 2019b).

\section{Conclusions}

Based upon the idea of not overlooking the aspect of control over content when it comes our ability to partake in a future social Internet, with all its conflicting features of incredible freedom to engage in democratic discourse on the one hand, and restrictions, bans, and surveillance on the other, this article has explored three possible scenarios for Internet governance. I find that more of the same, when it comes to either one of the first two scenarios where governments and private enterprise respectively are at the forefront of developments, will, from the perspective of Balkin's (2018a, 2018b) new-school speech regulation, have potentially dire consequences for participation and accessibility. Managing content in all its forms, particularly on social media platforms, will be difficult without users and journalists being subjected to various forms of continuously expanding regulations and restrictions. While actions may be well intended, the inherent logic in needing to know more about speakers, including news media, in order to prevent certain content from appearing, coupled with ownership of the entire service to begin with, will unlikely increase transparency and accountability. A systematic sense of due process is moreover likely impossible, as control needs to be maintained over billions of users and their subsequent actions online. The introduction of automated content moderation may seem like a solution and a way for platforms to take more responsibility, but research shows that such methods may exacerbate the problems of lack of transparency already in existence today (Gorwa, Binns, \& Katzenbach, 2020). 
Regarding the third scenario, where more control is in various ways transferred to the speakers, the prospects arguably look far brighter when it comes to the freedom of expression and participation, ultimately strengthening transparency and accountability. However, such a model actualizes the issue of harmful content yet again, content that in various ways threatens individuals or groups, toxifies, and polarizes communication, potentially hindering participation and voices being heard. A decentralized system does not immediately 'solve' the proliferation of such content. What it may enable is for users themselves to engage more in moderation on platforms and communities they wish to join online, as well as more independence for news media.

The idea of treating the Internet as a public utility, as also discussed in the third scenario, nevertheless illustrates the potential of substantial change occurring in the relationship between speakers and governments in the future. If citizens and governments join efforts in the management of information by representative institutions at local all the way up to global level, the establishment of rules and regulations for participation and freedom of speech can become more anchored in the democratic process, instead of drifting away from it. Different types of hybrid models are also possible, such as in the example of very advanced forms of e-government increasing and facilitating transparency and possibilities for cooperation between citizens and government, as well as tech companies.

Lastly, two significant developments during the first half of 2020 provide avenues for future research. First of all, the Covid-19 pandemic and its consequences for citizens world wide will be a topic for research for many years to come. The pandemic can, in the context of Internet governance, be examined not only regarding the spread of disinformation and how it was handled by different countries and platforms in a time of crisis-examining potential changes in the power struggles between the three corners of Balkin's triangle-but it can also be studied in regards of the importance of accessibility and participation, as the Internet's function as a crucial site of public discourse, information, and everyday existence expanded as many citizens spent extensive time in the home. The second relevant development stems from the wave of protests against police violence and racial injustice following the killing of George Floyd in May in Minneapolis, Minnesota. Social media giants faced significant criticism for being sites of hateful content, in the case of Facebook followed also by numerous advertising boycotts by major international brands. In response, some of them took steps to ban and block users and content, such as when video streaming platform Twitch temporarily suspended U.S. President Donald Trump's channel, and social media site Reddit banned a pro-Trump forum (Allyn, 2020). Building upon the momentum of a movement of engaged groups, methods of involving civil society in content moderation can be examined, as also suggested by Gorwa (2019a) and Suzor (2020).

\section{Acknowledgments}

I would like to thank the two anonymous reviewers for providing feedback on earlier versions of this manuscript.

\section{Conflict of Interests}

The author declares no conflict of interests.

\section{References}

Allagui, I. (2014). Waiting for spring: Arab resistance and change. International Journal of Communication, 8, 983-1007.

Allcott, H., \& Gentzkow, M. (2017). Social media and fake news in the 2016 election. The Journal of Economic Perspectives, 31(2), 211-253.

Allyn, B. (2020, June 29). Reddit bans The_Donald, forum of nearly 800,000 Trump fans, over abusive posts. NPR. Retrieved from https://www.npr.org/2020/06/ 29/884819923/reddit-bans-the_donald-forum-ofnearly-800-000-trump-fans-over-abusive-posts

Al-Saqaf, W., \& Edwardsson, M. P. (2019). Could blockchain save journalism? An explorative study of blockchain's potential to make journalism a more sustainable business. In M. Ragnedda \& G. Destefanis (Eds.), Blockchain and Web 3.0: Social, economic, and technological challenges (pp. 97-113). London: Routledge.

Andersson Schwarz, J. (2017). Platform logic: An interdisciplinary approach to the platform-based economy. Policy \& Internet, 9(4), 374-394.

Are, C. (2020). A corpo-civic space: A notion to address social media's corporate/civic hybridity. First Monday, 25(6). https://doi.org/10.5210/fm.v25i6.10603

Arpagian, N. (2016). The delegation of censorship to the private sector. In F. Musiani, D. L. Cogburn, L. DeNardis, \& D. L. Cogburn (Eds.), The turn to infrastructure in Internet governance (pp. 155-165). Basingstoke: Palgrave Macmillan.

Assimakopoulos, S., Baider, F. H., \& Millar, S. (Eds.). (2017). Online hate speech in the European Union: $A$ discourse-analytic perspective. Cham: Springer.

Balkin, J. M. (2004). Digital speech and democratic culture: A theory of freedom of expression for the information society. New York University Law Review, 79(1), 1-55.

Balkin, J. M. (2014). Old school/new school speech regulation. Harvard Law Review, 127, 2296-2341. Retrieved from https://papers.ssrn.com/sol3/papers. cfm?abstract_id $=2377526$

Balkin, J. M. (2018a). Free speech in the algorithmic society: Big data, private governance, and new school speech regulation. UC Davis Law Review, 51, 1149-1210.

Balkin, J. M. (2018b). Free speech is a triangle. Columbia Law Review, 118, 2011-2055. Retrieved from https:// digitalcommons.law.yale.edu/fss_papers/5160 
Barlow, J. P. (1996). A declaration of the independence of cyberspace. Electronic Frontier Foundation. Retrieved from https://projects.eff.org/ barlow/ Declaration-Final.html

Bates, S., Bavitz, C., \& Hessekiel, K. (2017). Zero rating \& Internet adoption: The role of Telcos, ISPs, \& technology companies in expanding global Internet access (Research Publication No. 2017-9). Cambridge, MA: Berkman Klein Center. Retrieved from https://papers.ssrn.com/sol3/papers.cfm?abstract_ id $=3047847$

Birnhack, M. D., \& Elkin-Koren, N. (2003). The invisible handshake: The reemergence of the state in the digital environment. Virginia Journal of Law and Technology, 8, 1-57.

Blumler, J. G. (2015). Core theories of political communication: Foundational and freshly minted. Communication Theory, 25, 426-438.

Chadwick, A., \& Howard, P. (Eds.). (2009). Routledge handbook of Internet politics. London: Routledge.

Clegg, N. (2020, May 6). Welcoming the oversight board. About Facebook. Retrieved from https:// about.fb.com/news/2020/05/welcoming-theoversight-board

Coche, E. (2018). Privatised enforcement and the right to freedom of expression in a world confronted with terrorism propaganda online. Internet Policy Review, 7(4). https://doi.org/10.14763/2018.4.1382

Corbyn, J. (2016). The digital democracy manifesto. Jeremy for Labour. Retrieved from https://www. jeremyforlabour.com/digital_democracy_manifesto

Culpepper, P. D., \& Thelen, K. (2020). Are we all Amazon Primed? Consumers and the politics of platform power. Comparative Political Studies, 53(2), 288-318.

Deibert, R., Palfrey, J., Rohozinski, R., \& Zittrain, J. (Eds.). (2010). Access controlled: The shaping of power, rights, and rule in cyberspace. Cambridge, MA: MIT Press.

DeNardis, L. (2014). The global war for Internet governance. New Haven, CT: Yale University Press.

DeNardis, L. (2020). The Internet in everything: Freedom and security in a world with no off switch. New Haven, CT: Yale University Press.

DePillis, L. (2018, November 15). Amazon's biggest customer may soon be the US government. CNN. Retrieved from https://edition.cnn.com/2018/11/15/ business/amazon-government/index.html

Douek, E. (2019). Facebook's "oversight board": Move fast with stable infrastructure and humility. North Carolina Journal of Law \& Technology, 21(1), 1-78. Retrieved from https://papers.ssrn.com/sol3/ papers.cfm?abstract_id=3365358

Flessner, D. (2020, May 11). Chattanooga recognized as digital inclusion trailblazer for broadband services, high-speed internet access. Chattanooga Times Free Press. Retrieved from https://www. timesfreepress.com/news/business/aroundregion/ story/2020/may/11/chattanooga-digital-inclusiontrailblazer $/ 522730$

Gillespie, T. (2015). Platforms intervene. Social Media + Society, 2015, 1-2. https://doi.org/10.1177/ 2056305115580479

Gillespie, T. (2018). Custodians of the Internet: Platforms, content moderation, and the hidden decisions that shape social media. New Haven, CT: Yale University Press.

Goldsmith, J., \& Woods, A. K. (2020, April 25). Internet speech will never go back to normal. The Atlantic. Retrieved from https://www.theatlantic.com/ideas/ archive/2020/04/what-covid-revealed-aboutinternet/610549

Gorwa, R. (2019a). The platform governance triangle: Conceptualising the informal regulation of online content. Internet Policy Review, 8(2). https://doi.org/ 10.14763/2019.2.1407

Gorwa, R. (2019b). What is platform governance? Information, Communication \& Society, 22(6), 854-871.

Gorwa, R., Binns, R., \& Katzenbach, C. (2020). Algorithmic content moderation: Technical and political challenges in the automation of platform governance. Big Data \& Society, 7(1). https://doi.org/10.1177/ 2053951719897945

Greenspan, R. E. (2020, May 14). Twitch is launching an advisory council that includes top streamers in the wake of months of criticism over controversial bans. Business Insider. Retrieved from https:// www.businessinsider.com/twitch-safety-advisorycouncil-board-help-guide-policies-ban-2020-5? $r=U S \& I R=T$

Harmer, E., \& Lumsden, K. (2019). Introduction: Online othering. In K. Lumsden \& E. Harmer (Eds.), Online othering: Exploring violence and discrimination on the Web (pp. 1-33). Basingstoke: Palgrave Macmillan.

Hart, P. (2013). Amazon, WikiLeaks, the Washington Post and the CIA. FAIR. Retrieved from https://fair. org/home/amazon-wilkileaks-the-washington-postand-the-cia

Kaye, D. (2019). Speech police: The global struggle to govern the Internet. New York, NY: Columbia Global Reports.

Keipi, T., Näsi, M., Oksanen, A., \& Räsänen, P. (2017). Online hate and harmful content: Cross-national perspectives. Abingdon: Routledge.

Kennedy, M. (2019, November 1). New Russian law gives government sweeping power over Internet. NPR. Retrieved from https://www.npr.org/2019/11/ 01/775366588/russian-law-takes-effect-that-givesgovernment-sweeping-power-over-internet

Klonick, K. (2018). The new governors: The people, rules, and processes governing online speech. Harvard Law Review, 131, 1598-1670.

Kremenova, I., \& Gajdos, M. (2019). Decentralized networks: The future Internet. Mobile Networks and Applications, 24, 2016-2023. 
Kuiper Systems LLC. (2019). Application for authority to launch and operate a non-geostationary satellite orbit system in Ka-band frequencies. Kuiper Systems LLC: Redmond, WA. Retrieved from https://licensing.fcc.gov/myibfs/download.do? attachment_key=1773656

Lessig, L. (1998). The laws of cyberspace. Paper presented at the Taiwan Net '98 Conference, Taipei, Taiwan. Retrieved from https://cyber.harvard.edu/ works/lessig/laws_cyberspace.pdf

Lessig, L. (2000). Code is law: On liberty in cyberspace. Harvard Magazine. Retrieved from https:// harvardmagazine.com/2000/01/code-is-law-html

Linders, D. (2012). From e-government to wegovernment: Defining a typology for citizen coproduction in the age of social media. Government Information Quarterly, 29, 446-454.

Linders, D., Liao, C. Z. P., \& Wang, C. M. (2018). Proactive e-governance: Flipping the service delivery model from pull to push in Taiwan. Government Information Quarterly, 35, 68-76.

Merrill, K. (2016). Domains of control: Governance of and by the domain name system. In F. Musiani, D. L. Cogburn, L. DeNardis, \& D. L. Cogburn (Eds.), The turn to infrastructure in Internet governance (pp. 89-106). Basingstoke: Palgrave Macmillan.

Moore, M. (2018). Democracy hacked: Political turmoil and information warfare in the digital age. London: Oneworld Publications.

Morrison, A. H. (2009). An impossible future: John Perry Barlow's 'Declaration of the independence of cyberspace.' New Media \& Society, 11(1/2), 53-72.

Mosco, V. (2016). After the Internet: New technologies, social issues, and public policies. Fudan Journal of Humanities and Social Sciences, 10, 297-313.

Musiani, F. (2015). Giants, dwarfs and decentralized alternatives to Internet-based services: An issue of Internet governance. Westminister Papers in Culture and Communication, 10(1), 81-94.

Nothias, T. (2020). Access granted: Facebook's free basics in Africa. Media, Culture \& Society, 42(3), 329-348.

Oster, J. (2017). Which limits on freedom of expression are legitimate? Divergence of free speech values in Europe and the United States. In U. Kohl (Ed.), The net and the nation state: Multidisciplinary perspectives on Internet governance (pp. 72-91). Cambridge: Cambridge University Press.

Poster, M. (1997). Cyberdemocracy: Internet and the public sphere. In D. Porter (Ed.), Internet culture (pp. 201-218). New York, NY: Routledge.

Prasad, R. (2018). Ascendant India, digital India: How net neutrality advocates defeated Facebook's free basics. Media, Culture \& Society, 40(3), 415-431.

Pressman, A. (2019). Why Facebook, SpaceX and dozens of others are battling over Internet access from space. Fortune. Retrieved from https://fortune.com/2019/ 01/25/facebook-spacex-internet-access-space
Raman, A., Joglekar, S., De Cristofaro, E., Sastry, N., \& Tyson, G. (2019). Challenges in the decentralised web: The Mastodon case. In Internet Measurement Conference (IMC 2019) (pp. 217-229). New York: ACM. Retrieved from https://arxiv.org/abs/ 1909.05801

Romano, A. (2010). Asia. In P. Norris (Ed.), Public sentinel: News media and governance reform (pp. 353-376). Washington, DC: The World Bank.

Shahbaz, A., \& Funk, A. (2019). Freedom on the net: The crisis of social media. Washington, DC: Freedom House. Retrieved from https://freedomhouse. org/report/freedom-net/2019/crisis-social-media

Sunstein, C. R. (1995). The First Amendment in cyberspace. The Yale Law Journal, 104(7), 1757-1804.

Suzor, N. (2020). Lawless: The secret rules that govern our digital lives. Cambridge: Cambridge University Press.

Tang, A. (2019a, March 12). How to fix democracy: Inside Taiwan's new digital democracy. The Economist. Retrieved from https://www.economist.com/openfuture/2019/03/12/inside-taiwans-new-digitaldemocracy

Tang, A. (2019b, May 8). Digital social innovation to empower democracy [Video file]. Retrieved from https://www.ted.com/talks/audrey_tang_digital_ social_innovation_to_empower_democracy

Tang, A. (2020, June 1). How digital innovation can fight pandemics and strengthen democracy [Video file]. Retrieved from https://www.ted.com/talks/ audrey_tang_how_digital_innovation_can_fight pandemics_and_strengthen_democracy\#t-39393

Thomasson, E. (2018, March 8). Germany looks to revise social media law as Europe watches. Reuters. Retrieved from https://www.reuters.com/article/usgermany-hatespeech/germany-looks-to-revisesocial-media-law-as-europe-watchesidUSKCN1GK1BN

Trostle, H., Kienbaum, K., Andrews, M., \& Mitchell, C. (2019, December 17). Cooperatives fiberize rural America: A trusted model for the Internet era. Institute for Local Self-Reliance. Retrieved from https://muninetworks.org/reports/edit-reportcooperatives-fiberize-rural-america-trusted-modelinternet-era-updated-dec-2019

Ullman, S., \& Tomalin, M. (2019). Quarantining online hate speech: Technical and ethical perspectives. Ethics and Information Technology, 22, 69-80.

van der Wilk, A. (2018). Cyber violence and hate speech online against women. Brussels: European Parliament. Retrieved from https://op.europa.eu/en/ publication-detail/-/publication/1ccedce6-c5ed11e8-9424-01aa75ed71a1

Vargas-Leon, P. (2016). Tracking Internet shutdown practices: Democracies and hybrid regimes. In F. Musiani, D. L. Cogburn, L. DeNardis, \& D. L. Cogburn (Eds.), The turn to infrastructure in Internet governance (pp. 166-188). Basingstoke: Palgrave Macmillan.

Wattles, J. (2017, December 14). Net neutrality re- 
peal: Facebook, Amazon, Netflix and internet providers react. CNN. Retrieved from https://money. cnn.com/2017/12/14/technology/business/fcc-netneutrality-reactions/index.html

World Health Organization. (2020, February 2). Novel Coronavirus (2019-NCoV): Situation report 13. Geneva: World Health Organization. Retrieved from www.who.int/docs/default-source/coronaviruse/ situation-reports/20200202-sitrep-13-ncov-v3.pdf

York, J. C., \& Zuckerman, E. (2019). Moderating the public sphere. In R. F. Jørgensen (Ed.), Human rights in the age of platforms (pp. 137-161). Cambridge, MA: MIT Press.

Zuboff, S. (2019). The age of surveillance capitalism: The fight for the future at the new frontier of power. London: Profile Books.

Zuckerberg, M. [Mark]. (2018, November 15). A blueprint for content governance and enforcement [Facebook status update]. Retrieved from https://www. facebook.com/notes/mark-zuckerberg/a-blueprintfor-content-governance-and-enforcement/ 10156443129621634

\section{About the Author}

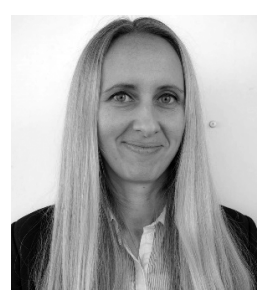

Emma Ricknell is a PhD Candidate at Linneaus University, Sweden. Her research interests include online communities, extremism, social media, and evolving forms of and conditions for political participation in the current media environment. Her past work includes a study analyzing discussions held on 4chan regarding the 2018 Swedish general election. 